\title{
Environmental change assessment in coastal lands; case study of the mound protected region
}

\begin{abstract}
The Mound Region is known as a coastal environment and natural evolved ecosystem with diverse habitats on the coast of the Persian Gulf. The ecosystem of this region is endangered by factors such as industrial development, the discharge of wastewaters and oil spills at sea, and the dumping of waste, the over development of agricultural and aquaculture products. The purpose of this study was to investigate the trend of coastal land use changes using satellite images of a 21-year period from 1996 to 2017 and using the maximum statistical probability and analyzes required in the ArcGIS10. The results showed that human-made uses in all periods of time have been increasing, and in the period 1996 to 2001, they had the slightest and the highest increase between 2006 and 2011 (391\%) and an increase of $1183 \%$ during the period from 2006 to 2011 . The major changes in the Northwest coastal areas due to the development of the oil and gas industry and the areas within the South Coast, agricultural and aquaculture activities have caused the most significant changes. As a result, periodic monitoring and control Contamination is recommended to reduce effects.
\end{abstract}

Volume 3 Issue 2 - 2019

\author{
Fatemeh Razavian,' Naser Ebadati, ${ }^{2}$ \\ Behnoush Khoshmanesh' \\ 'Department of Environmental Engineering, Islamic Azad \\ University Parand Branch, Iran \\ ${ }^{2}$ Geology Department, Islamic Azad University, Islamshahr \\ Branch, Iran
}

Correspondence: Naser Ebadati, Geology Department, Islamic Azad University, Islamshahr Branch, Iran, Email drebadat@iiau.ac.ir

Received: February 04, 2019 | Published: April 02, 2019

Keywords: mound area, persian gulf, coastal lands, GIS, environment change

\section{Introduction}

Coastal changes are one of the most common processes governing coastal areas. These changes can be subject to short and long term trends as well as varying dimensions. ${ }^{1,2}$ Location of the Persian Gulf coastal strip, various marine and continental climates, geological phenomena and how the land use are important parameters. One of the most important problems in land cover and vegetation cover is the lack of accurate, accurate information from the past. Changes monitoring is used to assess the effects of human activities such as deforestation, agriculture and urban planning. ${ }^{3,4}$ In the meantime, monitoring of coastal areas is an important part in sustainable development and environmental protection, and for coastal area monitoring, the extraction of coastline at different times is fundamental. ${ }^{5}$ Coastline is one of the most important linear effects on the surface of the earth, which shows the dynamic nature. ${ }^{6}$ Coastlines are defined by the International Commission of the IGDC for geographical data as one of the most important geographical features on the surface of the earth and geographically, the line of the coastline and the surface of the water zone. ${ }^{7}$ Based on this, coastline mapping and determining changes for safe navigation, resource management, environmental protection, sustainable coastal planning and development are essential. ${ }^{8}$ Studies to detect shore line changes in China using remote sensing data in the Delta River, Yellow River. ${ }^{9-11}$ And the sea of odors and on the Fujian coast. ${ }^{12-14}$ Makota et al. ${ }^{15}$ Reviewed aerial photos of 1981, 1992, and 2002 using the analytical capabilities of the GIS to monitor coastal changes in the Kundachi area. ${ }^{15}$ Chalby et al. ${ }^{16}$ Used aerial photos and satellite images using segmentation techniques to extract shore line changes and map out their changes for 8-year period (1992-2000) in Calgrange County, Malaysia. ${ }^{16}$ Schenthamilselvan \& Skakara ${ }^{17}$ studied in the Indian coast changes by using GIS and RS techniques. In the most cases, human degradation effects and changes in natural ecosystems are evident. ${ }^{17}$ Similar work has been done in Iran. Alsheikh et al. ${ }^{5}$ monitored the coastal lines of Lake Urmia, by TM and ETM satellite images, and the threshold method on the histogram. Taking into account changes in the coastline of the coastal region of Asaluyeh in the Persian Gulf using the detection of high and low position changes. ${ }^{5}$ Tamasoki et al. ${ }^{18}$ used Landsat images of 1985 ,
2000, and 2015 in their study to identify changes in the coastline of Lake Akigol. After analyzing the changes, it was found that there was a significant decrease in the lake water area studied. ${ }^{18}$ Finally, it was concluded that the coastline had significant spatial variations in some places up to more than $200 \mathrm{~m}$ for one The course is 30 years old. In another study, changes in the coastline of the port of Asalouyeh to the port of Deir in the Persian Gulf were investigated using RS and GIS techniques. The results showed that the area of human land was constructed and unutilized was added during the studied period and the area of vegetation, Water and pastures have been decreasing. ${ }^{19}$ According to the records, the purpose of this research is to investigate the process of coastal changes in a 21-year time span in the Persian Gulf coastal area.

\section{Materials and methods}

Classification of satellite images used by the Maximum Likelihood Classification method is a monitored statistical approach for pattern recognition..$^{20}$ In this category, the probability of belonging to each pixel is calculated in a set of predefined classes, and then the pixel is assigned to the most probable class. Using satellite imagery, five satellite imagery frames from Passage 163 and the $41^{\text {st }}$ Landsat Row for 1996-2017 were selected. Then radiometric and atmospheric corrections were performed on the images. For this purpose, ENVI software was used then, using ArcGIS $_{10.4}$ we performed the required output and analysis maps and overlapping data, and finally applied for statistical analysis of Microsoft Office Excel $_{2010}$ software.

\section{Geomorphology features}

The protected area is located south of Bushehr province and is south of the coastal area of the Persian Gulf. The immediate boundary of the studied area is the southern half of the Bushehr province, and from the north east to Fars province, from the south and west to the Persian Gulf and from the southeast to the part of Hormozgan province. This area, with an area of about $4.6 \mathrm{~km}^{2}$, hosts a population of 1000000 people in Bushehr Province and other neighboring provinces, and has more than $95 \mathrm{~km}$ of maritime border with the Persian Gulf. This study, in addition to the protected area of the whole of Bushehr Province, 
between $27^{\circ}, 19^{\prime}-30^{\circ}, 16^{\prime} \mathrm{N}$ latitude and $50^{\circ}, 11^{\prime}-52^{\circ}, 59^{\prime} \mathrm{E}$ longitude have been considered.

\section{Hydrodynamics of the mound coastal area}

The surface of the Persian Gulf is influenced by the level of offshore waters. Based on surveys, in the 18 -month period since the beginning of 2010 , the ocean surface has dropped by about $7 \mathrm{~mm},{ }^{20}$ the level of the Gulf Sea is also in line with it and has fallen under water during the period 1987-2006, and then the Gulf water level has fallen during the 2006-2015 period. These changes have led to an increase in the area and the coastal area in the Mound Delta. On the shores of Mound area, the flows along the sea parallel to the coast from the east to the west and along the left-turn round the general flow of the Persian Gulf, but the direction and velocity of the surface water flows Coastal is subject to the winds of the region, mainly westward to east. This mechanism determines the sedimentation process in the range of the Mound Delta, and sediments accumulate along the coasts and islands of the area. And this situation has created coastal geomorphological changes and it is necessary to consider of the development and land used.

\section{Results and discussion}

\section{Analysis and analysis of changes from 1996 to $200 \mathrm{I}$ : After examining the changes}

it is quite evident that the changes in the unutilized application were $42.8 \%$ and the utilization of pasture was $2.22 \%$ and the use of vegetation decreased by $24.66 \%$ and in the human uses $18.18 \%$ Percentages and the values for changes in usage are given in Table 1. According to Table 1, the breakdown of applications has led to the largest variation of vegetation on grassland and water, and manmade manure to unutilized, and unutilized and unutilized to rangeland (greater than grassland), and a full description of all the conversions between existing uses in the range The time from 1996 to 2001, broken down in Table 1, and the changes that took place during the time frame, are broken down by the location of the changes in Figure 1.

Table I User variations at the 1996-200I period $\left(\mathrm{Km}^{2}\right)$

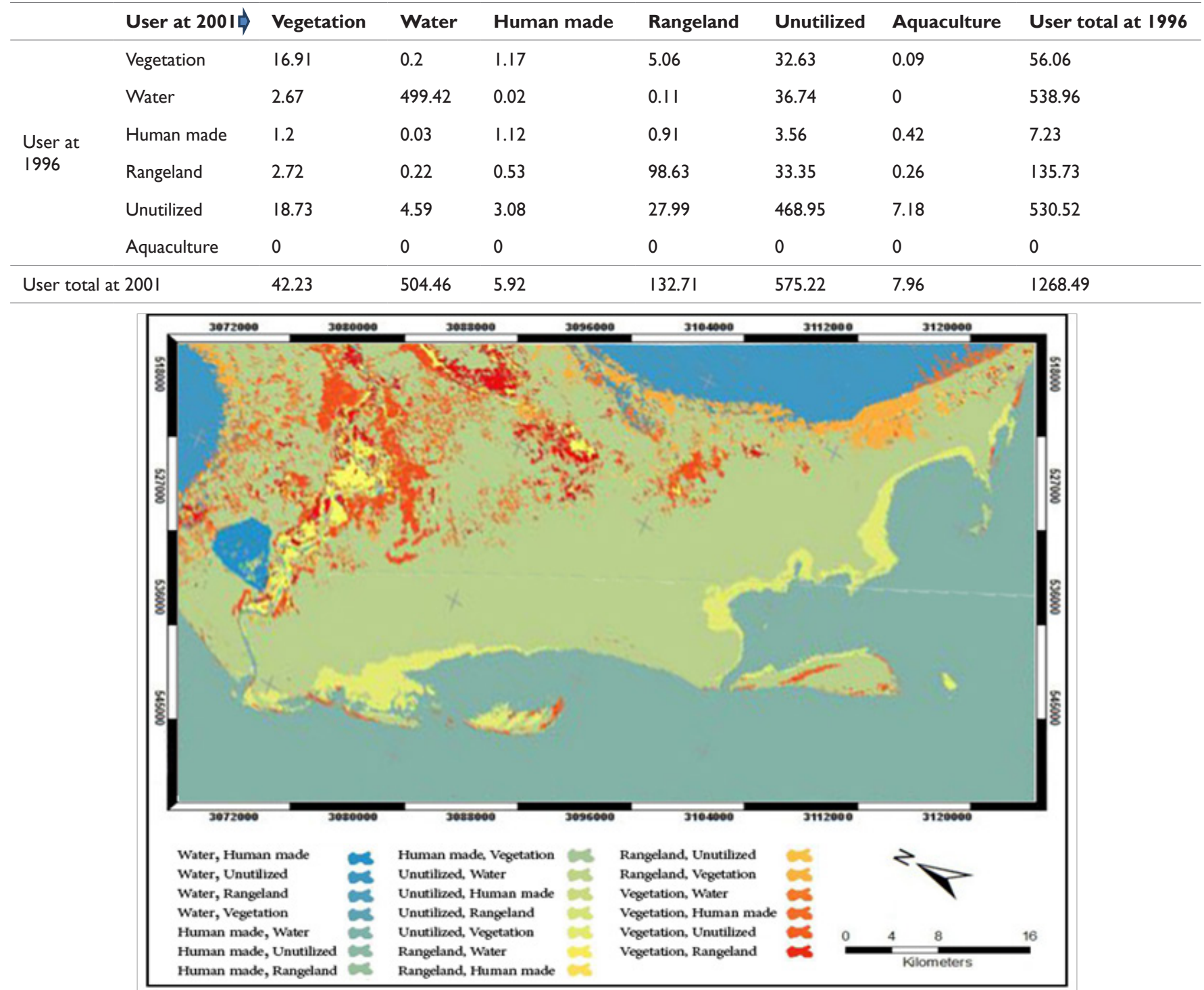

Figure I Change of user experience from 1996 to $200 \mathrm{I}$. 


\section{Analysis of changes from 2001 to 2006}

In the second stage and the period of 2006 to 2011, the process of changes has reduced the use of unutilized $(16.43 \%)$, and the decline in pasture use (18.47\%) and that it has the highest growth rate (143\%), as well as vegetation in this period has decreased $(11.83 \%)$, and the values for area changes Table 2 have changed. According to the breakdown table of applications, the largest change in vegetation is to beer and water to bewilder and man-made to the unutilized and Range to unutilized and unutilized. Also, the changes that have taken place during the time interval are separated by the location of the changes in Figure 2.

\section{Analyze changes made during the period 2006-20 I I}

After examining the changes, it is quite evident that the process of change has reduced the use of unutilized $(22.54 \%)$ and the increase in human-made use $(391.10 \%$ and all of them had the highest growth relative to their original area) and increased pasture use (20.70\%). Also vegetation has not changed in this period and has slightly increased. And the values for land use changes, expressed in square kilometers, are presented in the User Chart. According to the breakdown table of applications, the most varied vegetation changes to Bayer and Water to Bayer and human made to Bayer and Range to unutilized and unutilized to humans and Aquaculture to unutilized. And a full description of all the conversions between the existing applications in the period 2006 to 2011 is broken down in the Table 3. Changes that occurred during the time interval are based on the location of the changes in the Figure 3.

\section{Analyze changes made during the period from $20 \mathrm{II}$ to 2017}

After examining the changes, it is evident that the process of changes has increased the use of unutilized (51.27\%) and the reduction of the use of vegetation (the original reduction was the most significant compared to the rest of the uses $81.77 \%$ ) and the increase in human-made use $(31.27 \%)$ and decreased pasture use (10.66\%). And the values for user area changes are given in user modifications. According to the breakdown table of applications, the largest change in vegetation to unutilized and Water is to beer and human-made to unutilized and Range to unutilized and unutilized to human beet breeding and shrimp, and a full description of all the conversions between the use of the existing in the period from 2011 to 2017 is broken down in Table 4. Changes that occurred during the time interval are based on the location of the changes in the Figure 4. The total user changes are $1268.53 \mathrm{Km}^{2}$.

Table 2 User variations at the 200I-2006 period $\left(\mathrm{Km}^{2}\right)$

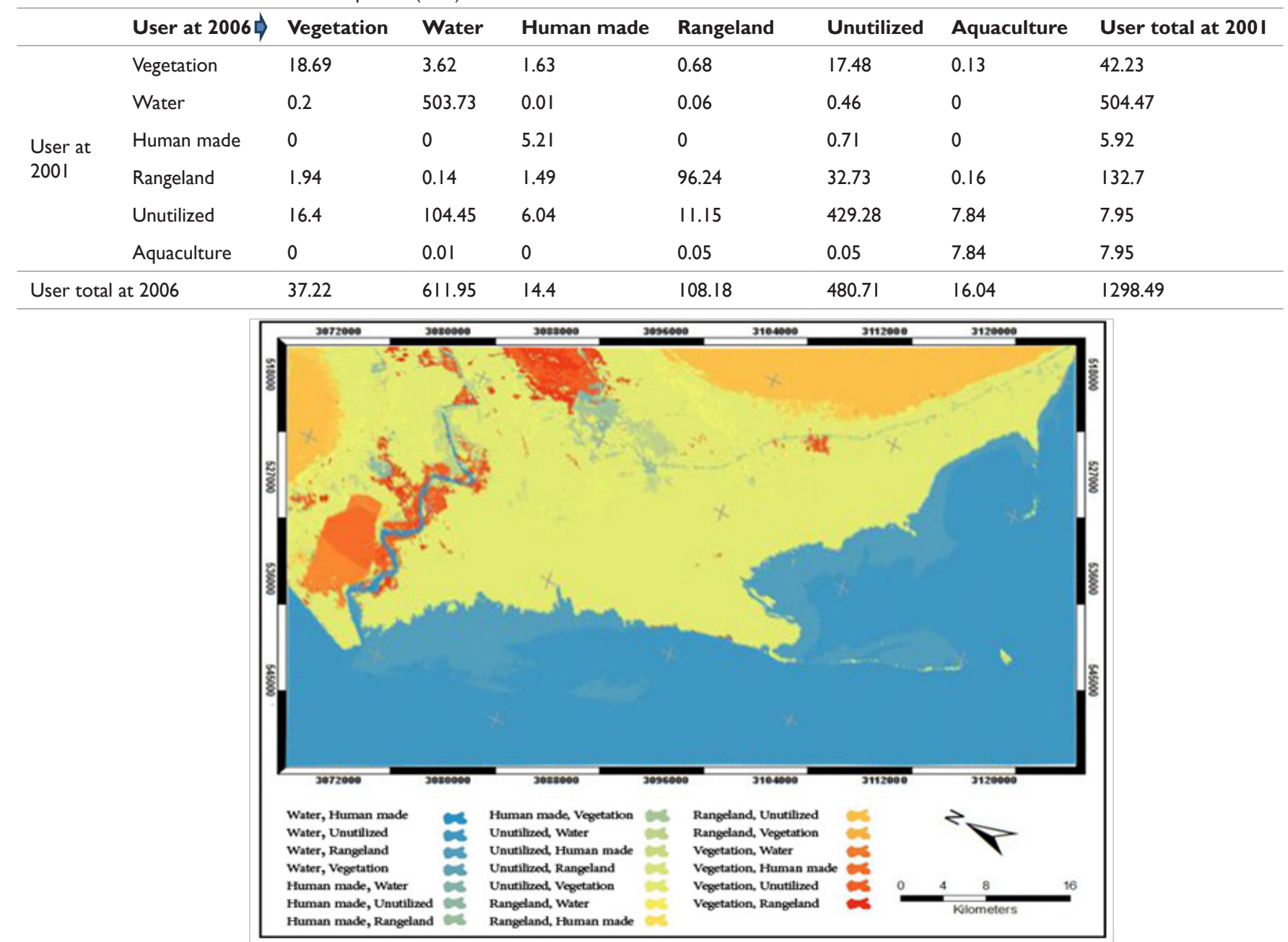

Figure 2 Change of user experience from 200I to 2006. 
Table 3 User variations at the 2006-20I I period $\left(\mathrm{Km}^{2}\right)$

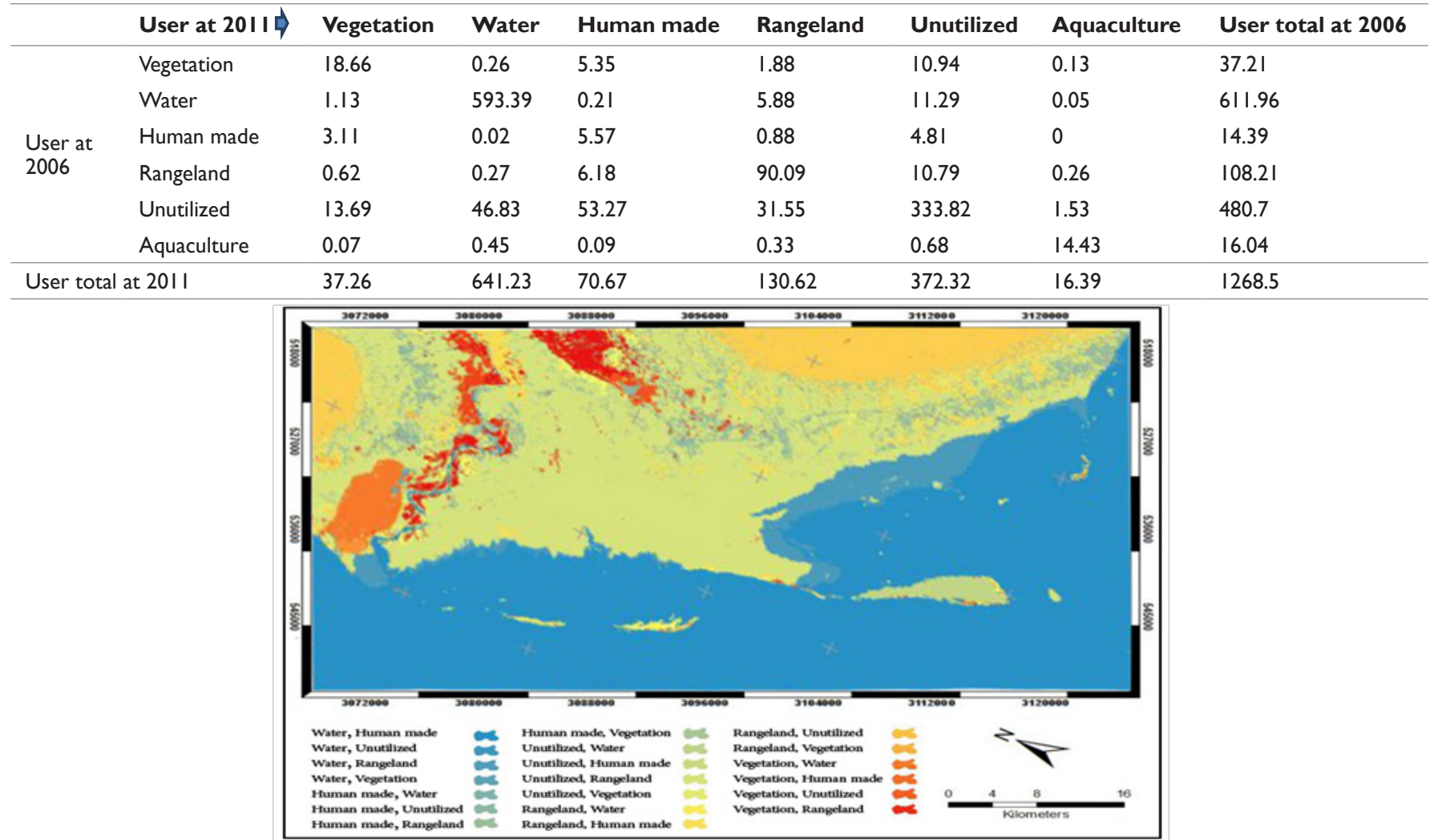

Figure 3 User changes from 2006 to 2011 .

Table 4 User-defined changes at the $201 \mathrm{I}-2017$ period $\left(\mathrm{Km}^{2}\right)$

\begin{tabular}{|c|c|c|c|c|c|c|c|c|}
\hline & User at 2017 & Vegetation & Water & Human made & Rangeland & Unutilized & Aquaculture & User total at $201 \mathrm{I}$ \\
\hline \multirow{5}{*}{$\begin{array}{l}\text { User at } \\
2011\end{array}$} & Vegetation & 4.08 & 0.05 & 11.83 & 7.11 & 14.04 & 0.15 & 37.26 \\
\hline & Water & 0.21 & 473.51 & 0.08 & 0.17 & 166.22 & 1.03 & 641.22 \\
\hline & Human made & 0.96 & 0.01 & 29.25 & 8.74 & 31.67 & 0.04 & 70.68 \\
\hline & Rangeland & 0.48 & 0.51 & 15 & 81.78 & 32.4 & 0.47 & 130.64 \\
\hline & Unutilized & 1.2 & 0.19 & 36.64 & 18.78 & 314.6 & 0.91 & 372.33 \\
\hline \multicolumn{2}{|c|}{ User total at 2017} & 6.94 & 474.33 & 92.81 & $1|6.7|$ & 563.25 & 14.49 & 1268.53 \\
\hline
\end{tabular}

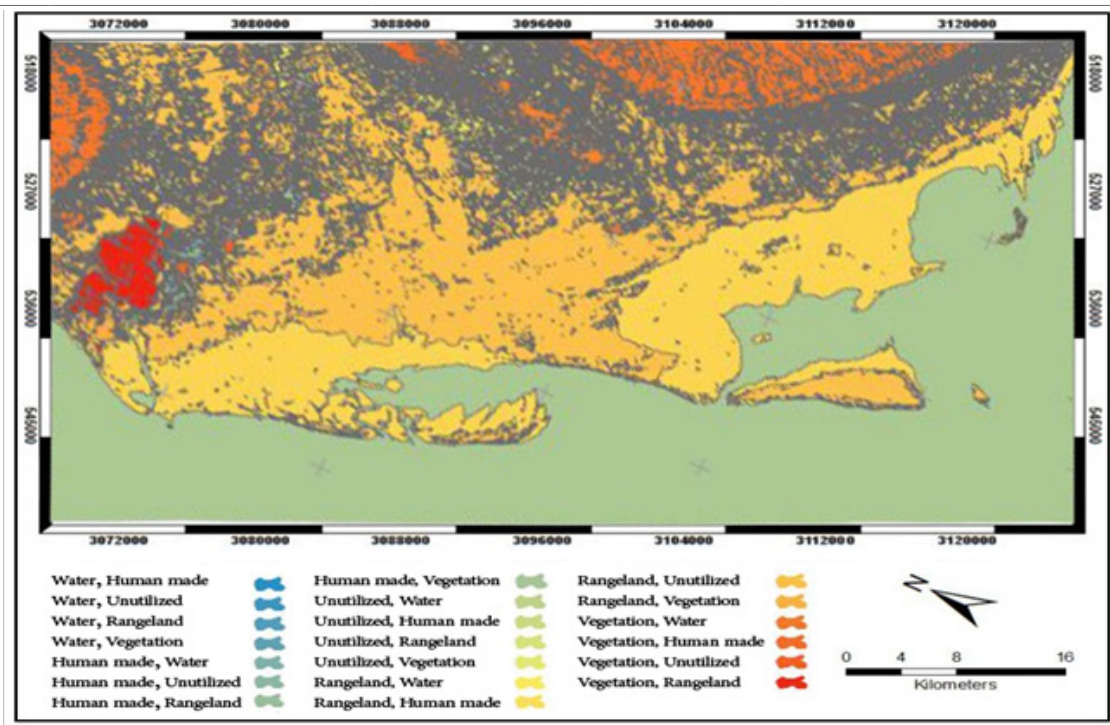

Figure 4 Map of User Changes from 20II to 2017.

Citation: Razavian F, Ebadati N, Khoshmanesh B. Environmental change assessment in coastal lands; case study of the mound protected region. Int J Hydro. 2019;3(2):I22-I27. DOI: I0.15406/ijh.2019.03.00I73 


\section{Analysis of changes in the period from 1996 to 2017}

After examining the changes, it is quite evident that the changes made to human consumption increase $(1183 \%)$ and the decrease in the use of vegetation (compared to the original area had the highest reduction compared to the rest of the user $87.62 \%$ and most of the time in the direction The loss of vegetation is related to the period from 2011 to 2017, the decrease in the use of pasture (14.03\%), and the increase in the use of unutilized $(16.6 \%)$, and the values of land use changes, expressed. And totally in the whole region aquaculture user have not changed. According to the breakdown table for use, the largest vegetation change is made to unutilized and Water to unutilized and human-made to unutilized and Pasture to unutilized and unutilized to human-made, and a full description of all the conversions between existing uses in the period 1996 to 2017, broken down in the Table 5. Changes that occurred during the time interval are based on the location of the changes in the Figure 5.

Table 5 User variations at the period up to $2017\left(\mathrm{Km}^{2}\right)$

\begin{tabular}{|c|c|c|c|c|c|c|c|c|}
\hline & User at 2017 & Vegetation & Water & Human made & Rangeland & Unutilized & Aquaculture & User total at 1996 \\
\hline \multirow{6}{*}{$\begin{array}{l}\text { User at } \\
1996\end{array}$} & Vegetation & 3.2 & 0.66 & $|5.5|$ & 5.82 & 30.57 & 0.29 & 56.06 \\
\hline & Water & 0.84 & 470.07 & 0.32 & 0.52 & 66.07 & 0.51 & 538.96 \\
\hline & Human made & 0.17 & 0.07 & 3.26 & 0.37 & 2.89 & 0.48 & 7.23 \\
\hline & Rangeland & 0.69 & 0.22 & 15.11 & 83.27 & 36.18 & 0.29 & 135.77 \\
\hline & Unutilized & 2.04 & 2.69 & 58.62 & 26.73 & 427.54 & $12.9 \mid$ & 530.53 \\
\hline & Aquaculture & 0 & 0 & 0 & 0 & 0 & 0 & 0 \\
\hline \multicolumn{2}{|c|}{ User total at 2017} & 6.94 & 474.33 & 92.82 & $|16.7|$ & 563.25 & 14.49 & 1268.54 \\
\hline
\end{tabular}

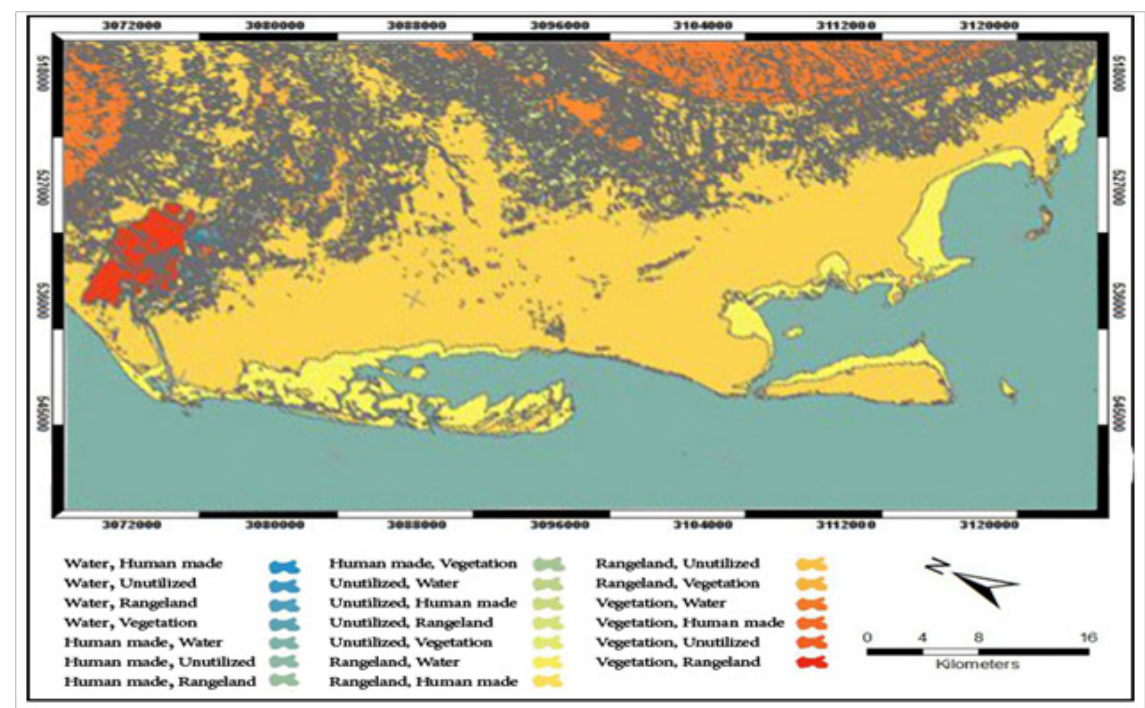

Figure 5 Map of User Changes from 1996 to 2017.

\section{Conclusion}

The results of this research have shown that man-made uses have been increasing over all periods of time, and during the period 1996 to 2001, they had the slightest and the highest increase between 2006 and 2011 (391\% growth over the period 2006-2011) and an increase of $1183 \%$ during the period from 1996 to 2017 , and due to the fact that most of this area is protected, the growth of human-made human development is considered to be the negative environmental consequences of the region. Often, in a given period, these changes and human resource development have been made by issuing permits such as breeding shrimp and livestock, or occupation and occupation of the area. In terms of vegetation use, the total vegetation cover decreased by $87.62 \%$ and the highest vegetation loss in the period from 2011 to 2017 , with a decrease of $37.78 \%$, mainly due to the growth of human consumption in the period 2006-2011, which reduced the vegetation of the region in the period has passed since then. And most of the changes in the Northwest coastal areas due to the development of oil and gas industry and the southern coastal areas have led to the most important changes in agricultural and aquaculture activities. As a result, periodic monitoring, pollution control and increasing popular participation are recommended to reduce the human-made effects.

\section{Acknowledgment}

Thus, the authors thank the officials of the General Directorate of the Natural Resources of Bushehr Province for their availability of existing information and documentation and are grateful to the National Offshore Oil Company for providing local access.

\section{Conflicts of interest}

The authors declare that there is no conflict of interest.

\section{References}

1. Arkema K, Guannel G, Verutes G, et al. Coastal habitats shield people and property from sea-level rise and storms. Nature. 2013;3(10):913-918. 
2. Jahromi V, Mousavi M, K Hosravi A. Monitoring of land use change in Kashan plain using remote sensing data. International Journal of Earthquake Research. 2014;4(2):129-137.

3. Arkhi S, Niazi Y, Arzani H. Comparison of Different Techniques for Monitoring Land Use Change, Vegetation Using RS and GIS Case Study: Valley of Shahr-Ilam Province. 2011;8(3):81-96.

4. Hajighaderi A. Preparation of Zanjan forests natural map using Landsat 7 ETM+ sensor data. Journal of Agricultural Science and Technology. 2007;11(42):62-76.

5. Alesheikh A, Ghorbanali A, Nouri N. Coastline change detection using remote sensing. Int J Science Technology. 2007;4(1):61-66.

6. Winarso G, Budhiman S. The potential application of remote sensing data for coastal study, Proc. 22nd. Asian Conference on Remote Sensing, Singapore. 2001.

7. Kurt S, Karaburun A, Demirci A. Coastline changes in Istanbul between 1987 and 2007. Scientific Research and Essays. 2010;5(19):3009- 3017.

8. Di K, Ruijing M, Jue W, et al. Coastal mapping and change diction using high resolution IKONOS satellite imagery. Semantic Scholor. 2004

9. Yang M, Van Zuidam R. Satellite remote sensing and GIS for the analysis of channel migration changes in the active Yellow River Delta, China. International Journal of Applied Earth Observation and Geoinformation 1999;1(2):146-157.

10. Li C, Xiao-Yan L. Coastline Change of the Yellow River Estuary and its Response to the Sediment and Runoff (1976-2005). Geomorphology. 2011;127(1-2):32-40.

11. Chong A. A case study on the establishment of shoreline position. $J$ Survey Review. 2004;37(293):542-551.
12. Jiang Yi, Li L, Hui K, et al. A remote sensing analysis of coastline change along the Bohai bay muddy coast in the past 130 years. Remote Sensing for Land \& Resources [CateGory Index]; P737. 2003;14(4):54-59.

13. Huang H, Fan H. Monitoring change of nearshore zone in the Huanghe (Yellow River) Delta since 1976. Oceanologia et Limnologia Sinica. 2004;35(4):306-314.

14. Sun M, Zhang W. Study on coastline remote sensing survey and application in Fujian Province. Journal of Oceanography in Taiwan Strait. 2004;23(2):213-219.

15. Makota V. Monitoring shoreline change using remote sensing and GIS a case study of Kunduchi area, Tansania. western Indian Ocean J Mar sci. 2004;3(1):1-10.

16. Chalabi A, Mohd-Lokman H, Mohd-Suffian I, et al. Monitoring shoreline change using IKONOS image and aerial photographs: a case study of Kuala Terengganu area, Malaysia. In ISPRS Commission VII Mid-term Symposium "Remote Sensing: From Pixels to Processes", Enschede, the Netherlands. 2006;8-11.

17. Schenthamilselvan R, Skakara B. Assessment of shoreline change along karantaka coast ,India using GIS, RS. Indian journal of marine sciences. 2013;43(7):14-20.

18. Tamassoki E, Amiri H, Soleymani Z. Monitoring of shoreline changes using remote sensing (case study: coastal city of Bandar Abbas). Earth and Environmental Science. 2016;20(4):12-23.

19. Ebadati N, Razavian F, Khoshmanesh B. Investigating the trend of coastline changes in the port of Asalouyeh to Bandar Deir using RS and GIS techniques. Iranian Journal of Echohydrology. 2018;5(2):652-662.

20. Yang J, Gong P, Fu R, et al. The role of satellite remote sensing in climate change studies. Nature Climate Change. 2013;3:875-883. 